\title{
Advanced oxidation processes: recent achievements and perspectives
}

\author{
Vítor J. P. Vilar ${ }^{1} \cdot$ Suresh C. Pillai ${ }^{2} \cdot$ loannis Poulios $^{3} \cdot$ Dionissios Mantzavinos $^{4} \cdot$ Albin Pintar $^{5}$ \\ Published online: 28 April 2020 \\ (C) Springer-Verlag GmbH Germany, part of Springer Nature 2020
}

Advanced oxidation processes (AOPs) and Electrochemical Advanced Oxidation Processes (EAOPs) are extensively applied for the decontamination of water, wastewater, air, and soil matrices. Photo-assisted advanced oxidation processes are considered as the preferred technology for large scale applications. The integration of AOPs/EAOPs with more mature technologies, such as ozonation, membrane filtration, and adsorption, towards process intensification, can drive the AOPs/EAOPs technologies market globally. These technologies also offer the possibility of using renewable energy sources such as solar light for pollutant remediation, thereby making it sustainable and green.

This special issue of Environmental Science and Pollution Research contains a selection of 7 papers presented at the 6th European Conference on Environmental Applications of Advanced Oxidation Processes (EAAOP-6), which was chaired by Dr. Albin Pintar and held in Portorož-Portorose, Slovenia, from 26th to 30th June 2019.

The history of EAAOP is very recent, starting in the year of 2006, organized by Prof. Dionissios Mantzavinos and Prof. Ioannis Poulios in the city of Chania (Greece). The second edition was organized in 2009 and chaired by Prof. Despo Fatta Kassinos in the city of Nicosia (Cyprus). The third meeting

\section{Responsible Editor: Philippe Garrigues}

Vítor J. P. Vilar

vilar@fe.up.pt

Suresh C. Pillai

pillai.suresh@itsligo.ie

Ioannis Poulios

poulios@chem.auth.gr

Dionissios Mantzavinos

mantzavinos@chemeng.upatras.gr

Albin Pintar

albin.pintar@ki.si was held in Almeria, Spain, in the year of 2013, chaired by Dr. Sixto Malato. Since then, the meetings have been held every two years. The fourth EAAOP was held in Athens, Greece (chaired by Profs. Mantzavinos and Poulios) and the fifth in Prague, Czech Republic (chaired by Prof. Josef Krysa).

The EAAOP-6 meeting brought together more than 300 academics, professionals, and policy makers from 51 countries such as Slovenia, Italy, France, Germany, Poland, Brazil, Greece, Spain, Portugal, Argentina, Mexico, USA, Canada, Japan and Korea. The conference program was rather comprehensive, offering a considerable variety of topics covered, with 4 plenary lectures, 4 keynote talks, 131 oral presentations, and 223 posters. The student paper contest was identified as an integral part of the event. The topics covered included (i) novel catalytic materials for environmental applications, (ii) in situ and operando measurements, (iii) advanced oxidation processes (water and air treatment, soil remediation, production of energy, and value added chemicals), (iv) photocatalysis, (v) disinfection, (vi) Fentonbased processes, (vii) ozonation, (viii) electrochemical processes, (ix) wet air and supercritical oxidation, (x) catalytic redox processes, (xi) plasma technologies, (xii) pilot-scale studies and field applications, and (xiii) process coupling/intensification.

1 Laboratory of Separation and Reaction Engineering-Laboratory of Catalysis and Materials (LSRE-LCM), Departamento de Engenharia Química, Faculdade de Engenharia, Universidade do Porto, Rua Dr. Roberto Frias, 4200-465 Porto, Portugal

2 Department of Environmental Science, Faculty of Science, Nanotechnology and Bio-Engineering Research Group, Institute of Technology Sligo, Ash Lane, Sligo, Ireland

3 Laboratory of Physical Chemistry, Department of Chemistry, Aristotle University of Thessaloniki, 54124 Thessaloniki, Greece

4 Department of Chemical Engineering, University of Patras, Caratheodory 1, University Campus, 26504 Patras, Greece

5 Laboratory for Environmental Sciences and Engineering, Department of Inorganic Chemistry and Technology, National Institute of Chemistry, Hajdrihova 19, SI-1001, Ljubljana, Slovenia 
The present collection includes articles dealing with the integration of photochemical, photo-catalytic, ozonation, electrochemical, membrane, and adsorption processes for pollutants removal from soil and water matrices. Although not exhaustive, the selection reflects the excellent perspectives for application of the processes described. Seven papers are included in this special edition entitled as (1) 1,4-dioxane removal from water and membrane fouling elimination using $\mathrm{CuO}$-coated ceramic membrane coupled with ozone, (2) synergy optimization for the removal of dye and pesticides from drinking water using granular activated carbon particles in a 3D electrochemical reactor, (3) UV-Cactivated persulfate oxidation of a commercially important fungicide: case study with iprodione in pure water and simulated tertiary treated urban wastewater, (4) improving ozonation to remove carbamazepine through ozone-assisted catalysis using different $\mathrm{NiO}$ concentrations, (5) assessment comparative of commercial $\mathrm{TiO}_{2}$ and $\mathrm{TiO}_{2}$ sol-gel on degradation of the caffeine using artificial radiation, (6) humic acids extracted from compost as amendments for Fenton treatment of diesel-contaminated soil, and (7) comparison between UVA- and zero-valent-ironactivated persulfate processes for degrading propylparaben.

Acknowledgments The guest editors would like to thank all the authors for the innovative scientific contributions to this special issue, the reviewers whose comments and suggestions were extremely important to achieve high-quality papers, as well as the institutions and companies that sponsored the EAAOP-6 meeting.

We also thank ESPR Editor-in-Chief Philippe Garrigues and the editorial assistants Fanny Creusot and Joanne Cabato-Berbon for their support in the preparation of this special issue.

Vítor J.P. Vilar wishes to thank the FCT Individual Call to Scientific Employment Stimulus 2017 (CEECIND/01317/2017).

Funding information The financial resources are provided by Associate Laboratory LSRE-LCM-UIDB/50020/2020 funded by national funds through FCT/MCTES (PIDDAC).

Publisher's note Springer Nature remains neutral with regard to jurisdictional claims in published maps and institutional affiliations.

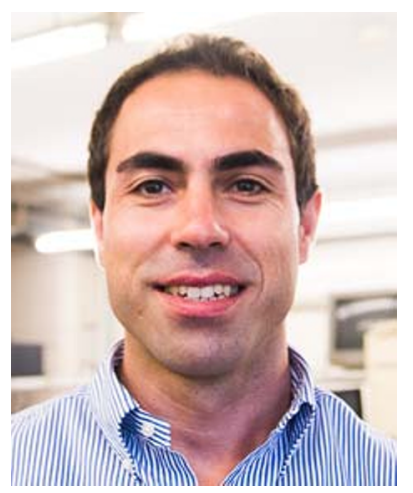

Vítor J.P. Vilar is principal researcher in the Laboratory of Separation and Reaction Engineering-Laboratory of Catalysis and Materials (LSRELCM), Faculty of Engineering, University of Porto (FEUP), since 2014. He earned his BSc in Chemical Engineering from the Faculty of Engineering of the University of Porto (FEUP) in 2001. He completed his PhD in Chemical Engineering at FEUP in 2006 , in Environmental Technologies. In 2014, he was awarded a three-year "Special Visiting Researcher" grant, at the Federal University of Santa Catarina, Brazil, sponsored by the Brazilian Ciência
Sem Fronteiras program. He is currently editor on Environmental Science and Pollution Research (ESPR) Journal (Springer). He has participated as a committee member or as program chair in nine international conferences on environmental engineering, delivering 38 plenary/keynote/invited lectures at international conferences and scientific institutions. He is member of the European Ph.D. School on AOPs and president of the Iberoamerican Conference on Advanced Oxidation Technologies (CIPOA). His research interest focuses on the environmental assessment and monitoring of surface waters and environmental friendly technologies for pollution control, particularly in the application of advanced oxidation processes and electrochemical oxidation processes for water and air treatment, integration of physical, chemical, biological, and membrane processes for the treatment of recalcitrant wastewaters, valorisation of natural materials for separation and recovery of heavy metals, oil and grease, soil remediation, process integration and intensification, water/waste recycling and valorization. He is author and co-author of more than 450 scientific publications, including 2 conference books, 10 book chapters, 7 editorials, 190 papers in peer-reviewed international scientific periodicals ( $h$ index: 42 and $>5800$ citations), 8 papers in national scientific periodicals, more than 260 contributions in conference proceedings and a co-inventor of 2 patents, receiving 8 prizes in total. He participated in different R\&D projects ( 9 international, 17 national and 5 contracts with private companies). He has mentored 24 researchers, 31 master students, 23 $\mathrm{Ph} . \mathrm{D}$. students, and 33 Postdoctoral researchers.

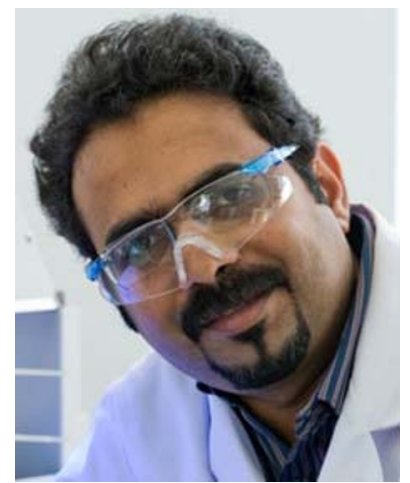

Prof. Suresh C. Pillai obtained his PhD in the area of Nanotechnology from Trinity College Dublin and then performed postdoctoral research at California Institute of Technology (Caltech), USA. Upon the completion of this appointment he returned to Trinity College Dublin as a Research Fellow before joining CRESTDIT as a Senior Research Manager in April 2004. Suresh joined IT Sligo as a Senior Lecturer in Nanotechnology in October 2013. He is an elected fellow of the UK's Royal Microscopical Society (FRMS) and the Institute of Materials, Minerals and Mining (FIMMM). Suresh was responsible for acquiring more than $€ 4$ million direct R\&D funding. He has published several scientific articles in leading peer reviewed journals and has presented papers in several international conferences. He has delivered over fifty international invited talks including several key-note and plenary talks. His research work was featured in the BBC London, BBC World Radio, Times UK, "The Investigators (RTE TV)" programme, RTE-1 TV News, Aljazeera TV, Ocean FM Radio and a number of national and international news media. He was also the recipient of the Boyle-Higgins Award 2019 from the Institute of Chemistry Ireland. He is an editor for the journal Environmental Science and Pollution Research (ESPR, Springer) and Editororial Board Member for the Chemical Engineering Journal and Applied Catalysis B (Elsevier). 


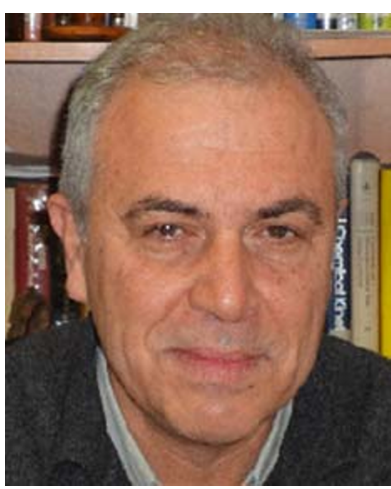

Ioannis Poulios is Professor in the Laboratory of Physical Chemistry at the Department of Chemistry at the Aristotle University of Thessaloniki. He received his Diploma in Chemical Engineering from the Technical University of Graz, Austria in 1979 and his Dr. Tech. degree from the same University in 1982. (Ph.D. thesis title: " $\mathrm{ZnO}$ Photoeffects under galvanostatic and potentiostatic conditions"). His research interests include photoelectrochemistry of semiconductors, photoelectrochemical solar ells, heterogeneous and homogeneous photocatalysis, solar detoxification and disinfection of wastewaters, drinking water, and air. He was organizer of 3 International Conferences on the Environmental Applications of the Advanced Oxidation Processes. He is acting as a referee for most of the journals in the area of environmental science, and was guest editor of 6 special issues. Prof. I. Poulios was in the period 2009-2017 director of the Division Physical, Analytical and Environmental Chemistry of the Chemistry Department and director of the Physical Chemistry Laboratory. Full current CV with publication lists can be found at http:// photocatalysisgroup.web.auth.gr

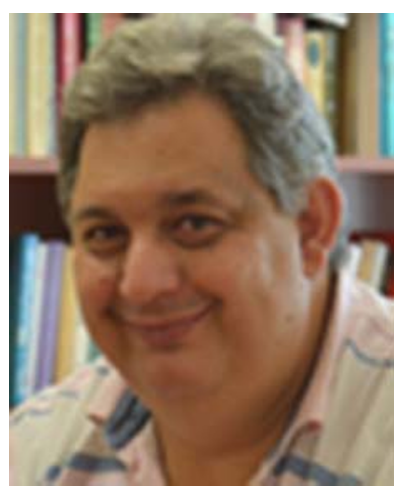

Prof. Dionissios Mantzavinos serves as a Professor of wastewater engineering in the Department of Chemical Engineering, University of Patras, Greece. He holds a Diploma (1991) in chemical engineering from Aristotle University of Thessaloniki, Greece, and M.S. (1993) and Ph.D. (1996) degrees in chemical engineering from Imperial College of Science, Technology, and Medicine, UK. After a short spell as a Research Fellow and Lecturer at Edinburgh and Leeds Universities, respective-

ly, he returned home to take up an academic position as an Assistant,
Associate, and Full Professor in the Department of Environmental Engineering at the Technical University of Crete before his move to University of Patras. His research interests focus on water/wastewater treatment by physical, chemical, and biological processes, as well as on environmental catalysis. Particular emphasis is given to advanced oxidation technologies including heterogeneous and homogeneous photocatalysis, electrochemical oxidation, ultrasound radiation, wet air oxidation, ozonation, and various combinations of the above.

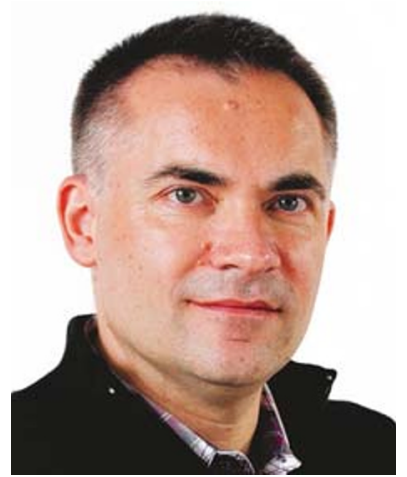

Dr. Albin Pintar, Research Professor, is head of the Laboratory for Environmental Sciences and Engineering at the National Institute of Chemistry, Ljubljana, Slovenia. He obtained his M.Sc. and Ph.D. degrees from the University of Ljubljana in 1992 and 1996, respectively. He was a visiting scientist at the Tokyo Institute of Technology (Japan) and Research Institute of Catalysis and Environment (Villeurbanne, France). His research interests are in the fields of heterogeneous catalysis, environmental catalysis, kinetics and mechanisms of catalytic reactions in multiphase reactors, wastewater treatment, production of hydrogen rich mixtures from renewables and process intensification. He is the author of over 160 scientific papers and review articles in peer-reviewed journals, and several international patents. Among others, he received a prestigious national award for significant scientific achievements in chemical engineering. Albin Pintar is president of the Slovenian Chemical Society and serves as associate editor to RSC Advances. 